\title{
Comparison of the Effects of Yokukansan and Yokukansankachimpihange on Glutamate Uptake by Cultured Astrocytes and Glutamate-Induced Excitotoxicity in Cultured PC12 Cells
}

\author{
Zenji Kawakami $\mathbb{D}^{D}$, Yuji Omiya, and Kazushige Mizoguchi \\ Tsumura Kampo Research Laboratories, Kampo Research \& Development Division, Tsumura \& Co., 3586 Yoshiwara, \\ Ami-machi, Inashiki-gun, Ibaraki 300-1192, Japan \\ Correspondence should be addressed to Zenji Kawakami; kawakami_zenji@mail.tsumura.co.jp
}

Received 15 January 2019; Revised 17 April 2019; Accepted 30 April 2019; Published 27 May 2019

Academic Editor: Toshiaki Makino

Copyright (c) 2019 Zenji Kawakami et al. This is an open access article distributed under the Creative Commons Attribution License, which permits unrestricted use, distribution, and reproduction in any medium, provided the original work is properly cited.

\begin{abstract}
The traditional Japanese Kampo medicine yokukansan (YKS) is effective for behavioral and psychological symptoms of dementia (BPSD) in patients with Alzheimer's disease. As the pharmacological mechanisms, YKS is known to protect astrocytes from thiamine-deficiency (TD)-induced decreased glutamate (Glu) uptake and neuron model cells (PC 12 cells) from Glu-induced death. Yokukansankachimpihange (YKSCH) is an alternative formula to YKS, in which Citrus unshiu peel and Pinellia tuber are added to the YKS components, and is sometimes used to treat BPSD, but its pharmacological properties remain unknown. This study aims to investigate the cellular pharmacological effects of YKS and YKSCH on glutamatergic pathways, compare their efficacy, and determine the differences and similarities in the activities between these formulations. First, we examined the effects of YKS and YKSCH on Glu uptake by cultured astrocytes under TD conditions. We observed significant ameliorative effects of YKS and YKSCH on the TD-induced decrease in Glu uptake, with a $50 \%$ effective dose of $8.9 \pm 1.8 \mu \mathrm{g} / \mathrm{mL}$ and $45.3 \pm 9.2 \mu \mathrm{g} / \mathrm{mL}$, respectively. Second, using cultured PC12 cells as a model for neurons, we examined the effects of YKS and YKSCH on Glu-induced cell death. We observed that YKS and YKSCH had significant inhibitory effects on Glu-induced cell death, with a $30 \%$ effective dose of 51.4 $\pm 20.8 \mu \mathrm{g} / \mathrm{mL}$ and $49.2 \pm 11.0 \mu \mathrm{g} / \mathrm{mL}$, respectively. Thus, while YKSCH was less effective than YKS in ameliorating the TD-induced decrease in Glu uptake by astrocytes, the two drugs showed similar inhibitory effects on Glu-induced PC12 cell death. These findings are important for understanding the differences and similarities in pharmacological actions between these drugs.
\end{abstract}

\section{Introduction}

Composed of seven kinds of dried medicinal plants, yokukansan (YKS) is one of the traditional Japanese Kampo medicines. YKS has been approved by the Japanese Ministry of Health, Labor, and Welfare as a remedy for neurosis and insomnia and for irritability and night crying in children. YKS is reported to improve the behavioral and psychological symptoms of dementia (BPSD) such as delusions, hallucinations, and agitation/aggressiveness in patients with Alzheimer's disease, Lewy bodies, and other forms of senile dementia $[1,2]$. These clinical findings are confirmed by two meta-analyses of randomized controlled trials [3, 4]. In animals, YKS is reported to ameliorate aggressive behaviors induced by thiamine-deficient (TD) $[5,6]$, zinc deficiency $[7,8]$, isolation stress [9], amyloid beta $(\mathrm{A} \beta)$ deposition in the brain [10], intracerebroventricular injection of $\mathrm{A} \beta$ oligomers [11], and glutamate (Glu) injection into the nucleus basalis of Meynert [12]. These observations are considered to reflect YKS effects on glutamatergic and serotonergic regulatory mechanisms. YKS was observed to attenuate excessive Glu release from presynaptic sites [7] and to improve reduced Glu uptake into astrocytes associated with Glu transporter dysfunction and Glu-induced neuronal death in cultures [13-15]. In the serotonergic system, for example, YKS exhibited partial agonistic actions for serotonin $1 \mathrm{~A}\left(5-\mathrm{HT}_{1 \mathrm{~A}}\right)$ receptors and upregulated these receptors $[9,16,17]$. YKS was also shown to downregulate $5-\mathrm{HT}_{2 \mathrm{~A}}$ 
receptor expression in the frontal cortical region of mice $[18,19]$.

Yokukansankachimpihange (YKSCH) is an alternative formula to YKS, containing an additional two medical herbs: Citrus unshiu peel (CUP) and Pinellia tuber (PT). In the theory of traditional medicines, CUP is thought to regulate qi (energy flow) and fortify the spleen and is used for the treatment of a variety of digestive dysfunctions including tympanites, nausea, vomiting, and dyspepsia [20,21]. PT is also thought to dry dampness, and dispel phlegm, and is used to treat coughs with copious sputum [21,22]. Although YKSCH is used for the same indications as YKS, the traditional uses of YKSCH differ somewhat. YKSCH is recommended for the treatment of patients with more severe loss of physical strength and more chronic conditions. Previous open-label trials showed that YKSCH improved BPSD such as delusions, irritability, and diurnal rhythm disturbance in patients with dementia [23-26]. A recent observational study showed that a combination of donepezil and YKSCH that contains Citrus reticulata instead of CPU significantly improved BPSD in patients with Alzheimer's disease, in which diurnal rhythm disturbance was significantly improved [27]. More recently, an open-label trial revealed that YKSCH tended to improve BPSD with significant improvement of apathy in Alzheimer's patients [28]. In animals, YKS and YKSCH produced the same degree of improvement in neuropsychiatric and gastrointestinal symptoms in TD rats [29]. In rats subjected to cholinergic degeneration in the nucleus basalis of Meynert, the ameliorative effect of YKSCH on aggressive behaviors is similar or somewhat weaker than that of YKS [12]. YKS but not YKSCH ameliorated the aggressive behavior of zincdeficient mice housed individually $[8,30,31]$. Taken together, these clinical and basic research findings suggest that $\mathrm{YKSCH}$ improves BPSD and BPSD-like symptoms but with slightly less efficacy than that of YKS.

The present study aims to investigate the pharmacological effects of YKSCH and to compare its efficacy and action to that of YKS. For this purpose, we focused on the glutamatergic mechanisms involved in the ameliorative effects of YKS on aggressiveness. Then, we evaluated and compared the effects of YKS and YKSCH on TD-induced decreases in Glu uptake by astrocytes and Glu-induced excitotoxicity in cultured neuron-related PC12 cells.

\section{Material and Methods}

2.1. Drugs and Reagents. YKS and YKSCH were supplied by Tsumura \& Co. (Tokyo, Japan). YKS is a dry powdered extract from a mixture of Atractylodes Lancea rhizome (4.0 g, rhizome of Atractylodes Lancea De Candolle), Poria sclerotium ( $4.0 \mathrm{~g}$, sclerotium of Poria cocos Wolf), Cnidium rhizome (3.0 g, rhizome of Cnidium officinale Makino), Uncaria hook ( $3.0 \mathrm{~g}$, thorn of Uncaria rhynchophylla Miquel), Japanese Angelica root (3.0 g, root of Angelica acutiloba Kitagawa), Bupleurum root (2.0g, root of Bupleurum falcatum Linné), and Glycyrrhiza (1.5 g, root and stolon of Glycyrrhiza uralensis Fisher). YKSCH comprises YKS with the two additional herbs, Pinellia tuber (PT; $5.0 \mathrm{~g}$, tuber of Pinellia ternate Breitenbach) and Citrus unshiu peel (CUP; $3.0 \mathrm{~g}$, peel of
Citrus unshiu Markovich). Extract qualities were standardized based on the good manufacturing practice as defined by the Japanese Ministry of Health, Labour, and Welfare. The yields of YKS and YKSCH were 15.9 and $15.8 \%$, respectively. In the present study, the concentration of $\mathrm{YKSCH}$ was set 1.4fold higher than that of YKS in order to equalize the YKS amount included in both extracts.

The three-dimensional high-performance liquid chromatography (3D-HPLC) profiles of the representative batch of YKS or YKSCH are shown in Figure 1. For the analysis of components, the dried extract $(1.0 \mathrm{~g})$ of YKS or YKSCH was extracted with methanol $(20 \mathrm{~mL})$ under ultrasonication for $30 \mathrm{~min}$ and was centrifuged at $3000 \mathrm{rpm}$ for $5 \mathrm{~min}$. The supernatants were filtered with a membrane filter $(0.45 \mu \mathrm{m})$ and then submitted for HPLC analysis $(30 \mu \mathrm{L})$. HPLC apparatus consisted of a Shimadzu LC 10A (analysis system software: CLASS-M10A ver. 1.64, Tokyo, Japan) equipped with a multiple wavelength detector (UV 200-400 nm) (Shimadzu SPDM10Avp, diode array detector), an auto injector (Shimadzu CTO-10AC). HPLC conditions were described as follows: column, ODS (TSK-GEL 80TS, $250 \times 4.6 \mathrm{~mm}$ i.d., TOSOH, Tokyo, Japan); eluent, (A) $0.05 \mathrm{M} \mathrm{AcONH}_{4}$ (pH 3.6) (B) $100 \% \mathrm{CH}_{3} \mathrm{CN}$. A linear gradient of $90 \%$ of $\mathrm{A}$ and $10 \%$ of $\mathrm{B}$ changing over $60 \mathrm{~min}$ to $0 \% \mathrm{~A}$ and $100 \% \mathrm{~B}$ was used. (And $100 \% \mathrm{~B}$ was continued for $20 \mathrm{~min}$.); temperature, $40^{\circ} \mathrm{C}$; flow rate, $1.0 \mathrm{~mL} / \mathrm{min}$. In the analysis, the maximum detection sensitivity of YKS was set at 600 milli-absorbance (mAbs), and that of YKSCH was set at $1300 \mathrm{mAbs}$ because of the high content of a CUP-derived flavonoid, hesperidin.

The compounds shown on the chromatogram were classified on the basis of the constituent herbs of YKS and YKSCH (Table 1), in which the compound compositions identified from both formulas differed. This is considered to be the difference in the detection sensitivity. Another possible reason is the influence of the combination of specific crude drugs on the extraction efficiency. For example, the addition of PT to a certain formula has been reported to lower $\mathrm{pH}$ values in the extract solution, which reduces extraction efficiency of the compounds derived from Uncaria hook [32] or Glycyrrhiza [33,34].

The reagents used in cell culture experiments, including DL-threo- $\beta$-hydroxy-aspartic acid (TBHA), dehydroquinate (DHK), pyrithiamine hydrobromide, Dulbecco's modified Eagle's medium (DMEM), DNase, glutamate dehydrogenase, $\beta$-nicotinamide adenine dinucleotide, 1-methoxyphenazine methosulphate, and Triton X-100, were purchased from Sigma-Aldrich (St. Louis, MO, USA). EDTA, HEPES, and 3(4,5-dimethylthial)-2,5-diphenyltetrazalium bromide (MTT) were purchased from Dojindo (Kumamoto, Japan). Other chemicals were purchased from commercial sources.

\subsection{Preparation of Primary Cultured Astrocytes. Primary} cultured astrocytes were prepared according to the procedure described previously [35] with some modifications [13]. In brief, newborn-rat neopallia were mechanically disrupted by pipetting in DMEM/Ca- and Mg-free phosphate buffered saline $[\mathrm{PBS}(-)](1: 1)$. The suspension was filtered through a sterile nylon mesh with $100 \mu \mathrm{m}$ pores (Corning, Corning, NY, USA). The filtrate was passed through sterile lens cleaning 


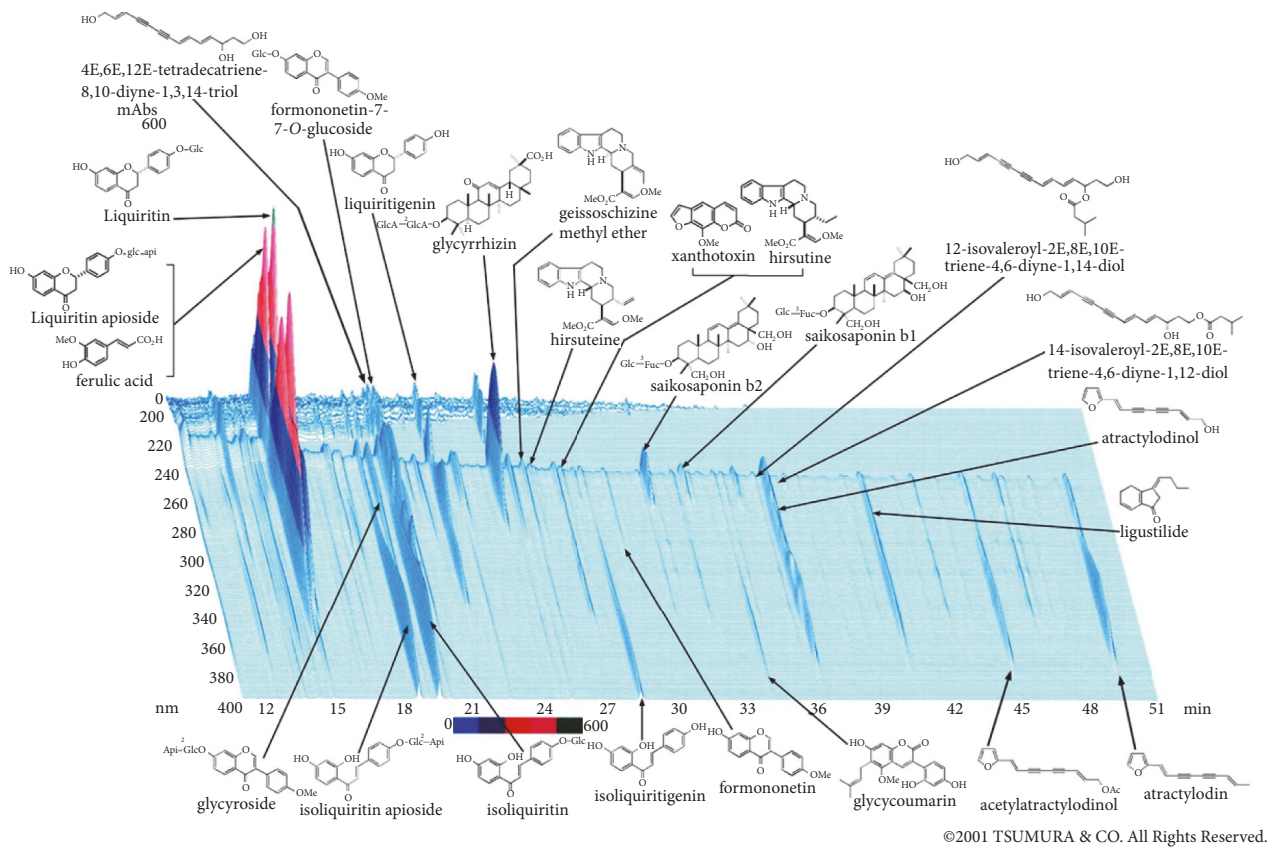

(a)

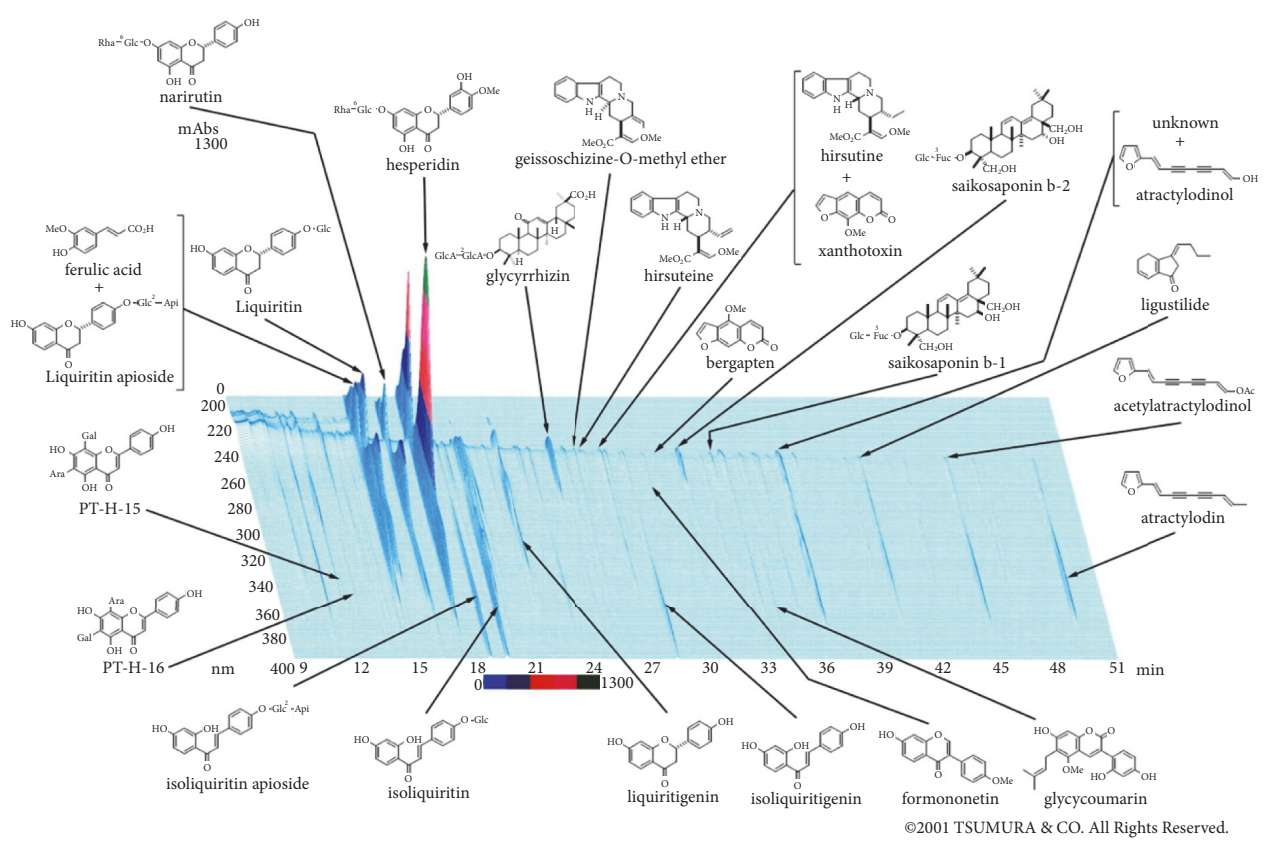

(b)

Figure 1: The three-dimensional HPLC profiles of YKS (a) and YKSCH (b).

paper (Fujifilm, Tokyo, Japan). Cells $\left(3.75 \times 10^{6}\right)$ were seeded into a $75-\mathrm{cm}^{2}$ culture flask (Corning) with DMEM containing $7.5 \mathrm{mM}$ glucose, $2 \mathrm{mM}$ glutamine, $25 \mathrm{mM} \mathrm{NaHCO} 3$, and $10 \%$ horse serum. The next day, the culture medium was replaced with DMEM containing $25 \mathrm{mM}$ sorbitol, $2 \mathrm{mM}$ glutamine, $25 \mathrm{mM} \mathrm{NaHCO}_{3}$, and $10 \%$ dialyzed horse serum, and the cells were incubated for 2 weeks. After the incubation period, the cultures were returned to the glucose-containing DMEM medium, and the purity of astrocytes in the culture was examined by immunocytochemical staining using an antibody to glial fibrillary acidic protein (GFAP), a specific marker for astrocytes (Supplementary Figure 1). We confirmed that at least $95 \%$ of the cells were astrocytes.

The high-purity cultured astrocytes were harvested from the substratum using Puck's solution ( $\mathrm{pH}$ 7.2) containing $3 \mathrm{mM}$ EDTA, $2 \mathrm{mM}$ pyruvate, $7.5 \mathrm{mM}$ glucose, $0.02 \%$ DNase, and $10 \mathrm{mM}$ HEPES. Approximately $20000 \mathrm{cells} / \mathrm{cm}^{2}$ were seeded into 96-well Primaria culture plates (Corning) and 
TABLE 1: Classification of the compounds identified in three-dimensional chromatogram.

\begin{tabular}{|c|c|c|}
\hline \multirow{2}{*}{ Constituent herbs } & \multicolumn{2}{|c|}{ Compounds } \\
\hline & Yokukansan & Yokukansankachimpihange \\
\hline $\begin{array}{l}\text { Atractylodes Lancea } \\
\text { rhizome }\end{array}$ & $\begin{array}{l}\text { 4E,6E,12E-tetradecatriene-8,10-diyne-1,3,14- } \\
\text { triol, 12-isovaleroyl-2E,8E,10E- triene-4,6- } \\
\text { diyne-1,14-diol, 14-isovaleroyl-2E,8E,10E- } \\
\text { triene-4,6-diyne-1,12-diol, acetylatractylodin, } \\
\text { atractylodin, atractylodinol }\end{array}$ & acetylatractylodin, atractylodin, atractylodinol \\
\hline Cnidium rhizome & ferulic acid, ligustilide & ferulic acid, ligustilide \\
\hline Uncaria hook & $\begin{array}{l}\text { geissoschizine methyl ether, hirsuteine, } \\
\text { hirsutine }\end{array}$ & $\begin{array}{l}\text { geissoschizine-O-methyl ether, hirsuteine, } \\
\text { hirsutine }\end{array}$ \\
\hline Japanese Angelica root & ligustilide, xanthotoxin & bergapten, ligustilide, xanthotoxin \\
\hline Bupleurum root & saikosaponin b1, saikosaponin b2 & saikosaponin b1, saikosaponin b2 \\
\hline Glycyrrhiza & $\begin{array}{l}\text { formononetin, formononetin-7-O-glucoside, } \\
\text { glycycoumarin, glycyroside, glycyrrhizin, } \\
\text { isoliquiritigenin, isoliquiritin, isoliquiritin } \\
\text { apioside, liquiritigenin, liquiritin, isoliquiritin } \\
\text { apioside, }\end{array}$ & $\begin{array}{l}\text { formononetin, glycycoumarin, glycyroside, } \\
\text { glycyrrhizin, isoliquiritigenin, isoliquiritin, } \\
\text { isoliquiritin apioside, liquiritigenin, liquiritin, } \\
\text { isoliquiritin apioside, }\end{array}$ \\
\hline Pinellia tuber & & PT-H-15, PT-H-16 \\
\hline Citrus unshiu peel & & hesperidin, narirutin \\
\hline
\end{tabular}

used in the following experiments after the cells became confluent.

2.3. Glu Uptake in Cultured Astrocytes. TD-subjected astrocytes were prepared according to the procedure described by Hazell [36] to induce TD as follows: confluent astrocytes were reseeded onto 96-well plates and cultured for 5 days in a custom-designed DMEM medium lacking in thiamine (CSTI, Sendai, Japan) and containing 5\% horse serum in the presence of $10 \mu \mathrm{M}$ pyrithiamine, an inhibitor of the enzyme that produces the active form of thiamine. Control astrocytes were cultured for the same amount of time in DMEM medium including thiamine and containing $5 \%$ horse serum. TD astrocytes were treated with YKS or YKSCH as follows: astrocytes were cultured for 5 days in TD medium with various concentrations of YKS or YKSCH that had been filtered through a $0.22-\mu \mathrm{m}$ filter.

Glu uptake was evaluated in cells after culturing for 5 days. Thus, $100 \mu \mathrm{M}$ Glu was exogenously added to astrocyte cultures. After incubating for $5 \mathrm{~h}$, an aliquot of the culture medium was carefully collected. The extracellular concentration of Glu was determined according to a colorimetric method described previously [37] with minor modifications. In brief, $50 \mu$ l of the medium was mixed with an equal volume of substrate mixture containing $20 \mathrm{U} / \mathrm{mL}$ glutamate dehydrogenase, $2.5 \mathrm{mg} / \mathrm{mL} \beta$-nicotinamide adenine dinucleotide, $0.25 \mathrm{mg} / \mathrm{mL}$ MTT, $100 \mu \mathrm{M}$ 1-methoxyphenazine methosulfate, and $0.1 \%$ Triton X-100 in $0.05 \mathrm{M}$ Tris- $\mathrm{HCl}$ buffer $(\mathrm{pH}$ 8.2). The mixture was incubated at $37^{\circ} \mathrm{C}$ for $10 \mathrm{~min}$, and the reaction was stopped by adding $100 \mu \mathrm{L}$ of a stop solution $(\mathrm{pH}$ 4.7) containing 50\% dimethylformamide and $20 \%$ sodium dodecyl sulfate (SDS). The amount of formazan produced from MTT by Glu was colorimetrically determined at a test wavelength of $540 \mathrm{~nm}$ and a reference wavelength of $690 \mathrm{~nm}$ using a microplate reader. The Glu concentration of each sample was estimated from the standard curve constructed for each assay using cell-free medium containing known concentrations of L-glutamate.

The average Glu concentration of the TD-induced astrocyte $\left(\mathrm{OD}_{\mathrm{TD}}\right)$ sample was subtracted from the Glu concentration of the test-substance-treated sample $\left(\mathrm{OD}_{\text {test }}\right)$ or the average Glu concentration of the control to calculate the extent of amelioration, as follows: Amelioration (\%) $=100-$ $\left[\left(\mathrm{OD}_{\text {test }}-\mathrm{OD}_{\mathrm{TD}}\right) /\left(\mathrm{OD}_{\text {control }}-\mathrm{OD}_{\mathrm{TD}}\right)\right] \times 100$.

2.4. Glu-Induced PC12 Cell Death. PC12 cells were obtained from Dainippon Sumitomo Pharma (Osaka, Japan) and maintained at $37^{\circ} \mathrm{C}$ in $95 \%$ air and $5 \% \mathrm{CO}_{2}$ with $95 \%$ relative humidity in RPMI 1640 medium (Thermo Fisher Scientific, Waltham, MA, USA) supplemented with $5 \%$ fetal calf serum, $10 \%$ heat-inactivated horse serum, penicillin $(50 \mathrm{U} / \mathrm{mL})$, and streptomycin $(50 \mu \mathrm{g} / \mathrm{mL})$ until used in experiments.

On the day of the experiments, PC12 cells were seeded into 96-well microplates (5,000 cells/well in $100 \mu \mathrm{L}$ medium) in RPMI 1640 medium supplemented with 5\% dialyzed fetal calf serum, $10 \%$ dialyzed horse serum, penicillin $(50 \mathrm{U} / \mathrm{mL})$, and streptomycin $(50 \mu \mathrm{g} / \mathrm{mL})$ without phenol red. Fortyeight hours after seeding, the medium was replaced with one of three types of fresh culture medium (medium without Glu as a control, medium with $8 \mathrm{mM} \mathrm{Glu}$, and medium with $8 \mathrm{mM}$ Glu plus various concentrations of YKS or YKSCH) and the cells incubated for $24 \mathrm{~h}$. Cell survival then was evaluated using the MTT reduction assay [38].

The MTT reduction assay was performed as follows. To each well of a 96 -well plate was added $20 \mu \mathrm{L}$ of $5 \mathrm{mg} / \mathrm{mL}$ MTT dissolved in PBS(-), followed by incubation at $37^{\circ} \mathrm{C}$ for $5 \mathrm{~h}$. The reaction was stopped by the addition of $100 \mu \mathrm{L}$ of solubilization solution ( $10 \%$ SDS in $0.01 \mathrm{~N} \mathrm{HCl})$. The blue 


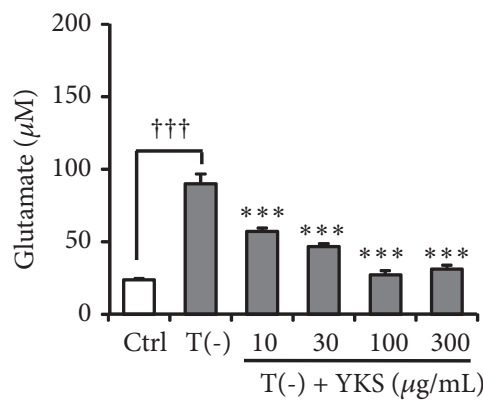

(a1)

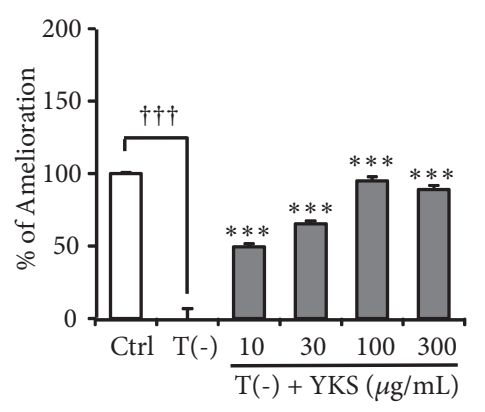

(b1)

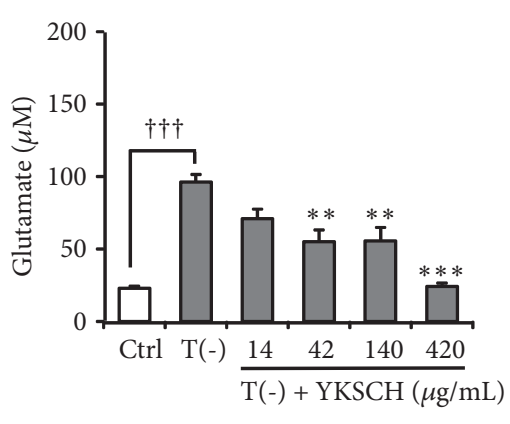

(a2)

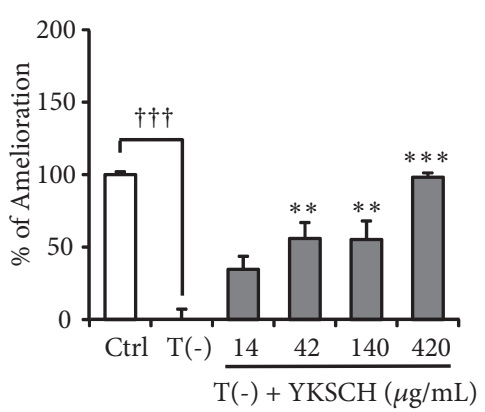

(b2)

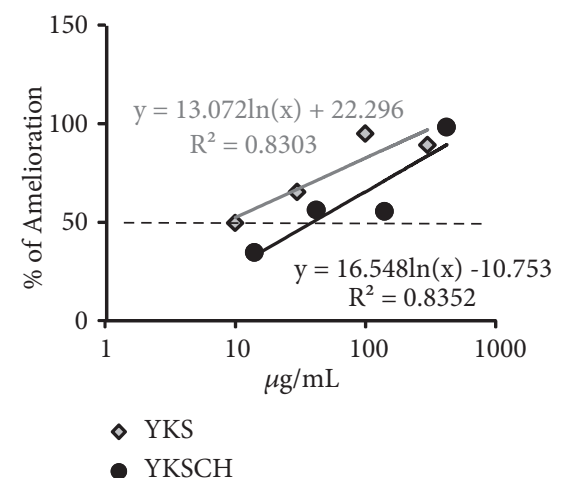

(c)

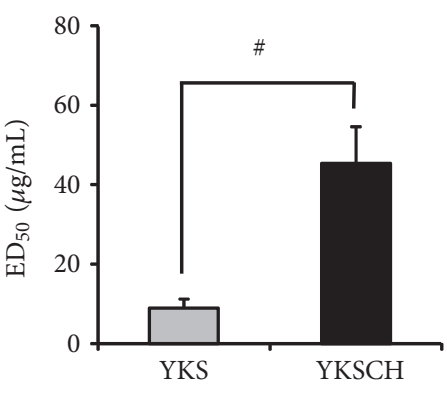

(d)

FIGURE 2: Effects of YKS or YKSCH on TD-induced decrease in Glu uptake by cultured astrocytes. Astrocytes were cultured for 5 days in (1) Ctrl: thiamine-containing normal medium, (2) T(-): TD medium, or (3) T(-) medium containing YKS (10-300 $\mu \mathrm{g} / \mathrm{mL})$ or YKSCH (14-420 $\mu \mathrm{g} / \mathrm{mL})$. (a1); (a2) Glu concentration of cultured Glu-containing medium (100 $\mu \mathrm{M}$ ) for $5 \mathrm{~h}$. (b1); (b2) Amelioration rate as determined from Glu concentration. (c) $50 \%$ effective dose $\left(\mathrm{ED}_{50}\right)$ as calculated from the regression equation for the amelioration rate. $(\mathrm{d})$ Average $\mathrm{ED}_{50}$ compared between YKS and YKSCH. Data are presented as the mean \pm SEM ((a1), (a2), (b1), and (b2): $\mathrm{n}=6 ;(\mathrm{d}): \mathrm{n}=5) .{ }^{\dagger \dagger \dagger} P<0.001 \mathrm{vs}$. Ctr; $* * P<0.01$ and $* * * P<0.001$ vs. T(-): one-way ANOVA + Dunnett's test. ${ }^{\#} P<0.05$ vs. YKS: Student's $t$-test.

formazan formed from MTT by the reaction was dissolved by additional incubation for $18 \mathrm{~h}$ at $37^{\circ} \mathrm{C}$. The absorbance of the formazan solution was measured using an Infinite M200 microplate reader (Tecan, Grödig, Austria) at a test wavelength of $540 \mathrm{~nm}$ and a reference wavelength of $690 \mathrm{~nm}$.

The average absorbance of the Glu-induced cell death $\left(\mathrm{OD}_{\mathrm{Glu}}\right)$ was subtracted from the absorbance of the testsubstance-treated sample $\left(\mathrm{OD}_{\text {test }}\right)$ or the average control absorbance $\left(\mathrm{OD}_{\text {control }}\right)$ to calculate the $\%$ amelioration, as follows: Amelioration $(\%)=\left[\left(\mathrm{OD}_{\text {test }}-\mathrm{OD}_{\mathrm{Glu}}\right) /\left(\mathrm{OD}_{\text {control }}{ }^{-}\right.\right.$ $\left.\left.\mathrm{OD}_{\mathrm{Glu}}\right)\right] \times 100$.

2.5. Statistical Analysis. Data are presented as the mean \pm SEM. The statistical significance of differences between groups in cell culture experiments was assessed by Student's $t$-test or one-way analysis of variance (ANOVA) followed by Dunnett's post hoc test. $P<0.05$ was considered significant.

\section{Results}

3.1. Effect of Drugs on TD-Induced Decrease in Glu Uptake by Astrocytes. Under TD conditions, the extracellular Glu concentration remained approximately $100 \mu \mathrm{M}$, the initial concentration of the medium, indicating that Glu uptake into TD astrocytes was almost completely inhibited. YKS and YKSCH treatment significantly decreased extracellular Glu in a concentration-dependent manner $\left(F_{(5,30)}=51.364, P<0.001\right.$ and $F_{(5,30)}=20.747, P<0.001$, respectively) (Figures $2(\mathrm{al})$ and $2(\mathrm{a} 2))$, suggesting that both drugs ameliorated TD-induced impairment of glutamate uptake by astrocytes. The Glu concentration of the medium was converted to amelioration rate to allow comparison between the experiments (Figures 2(b1) and $2(\mathrm{~b} 2))$. The $50 \%$ effective dose $\left(\mathrm{ED}_{50}\right)$ for amelioration was calculated using the regression equation for the amelioration rate (Figure 2(c)). Each experiment was repeated 5 times, and the average $\mathrm{ED}_{50}$ was calculated (average $\mathrm{ED}_{50}$ : YKS, $8.9 \pm 1.8 \mu \mathrm{g} / \mathrm{mL}$; YKSCH, $45.3 \pm 9.2 \mu \mathrm{g} / \mathrm{mL})$. The $\mathrm{ED}_{50}$ differed significantly between YKS and YKSCH $(P<0.05)$ (Figure 2(d)).

The inhibitory effects of CUP and PT, both of which are components of $\mathrm{YKSCH}$, on TD-induced impairment of Glu uptake by astrocytes were examined. The TD-induced decrease in Glu uptake was ameliorated by PT $\left(F_{(5,30)}=\right.$ $10.744 ; P<0.001)$ but not by CUP $\left(F_{(5,30)}=10.544 ; P<0.001\right)$ (Figure 3 ). 


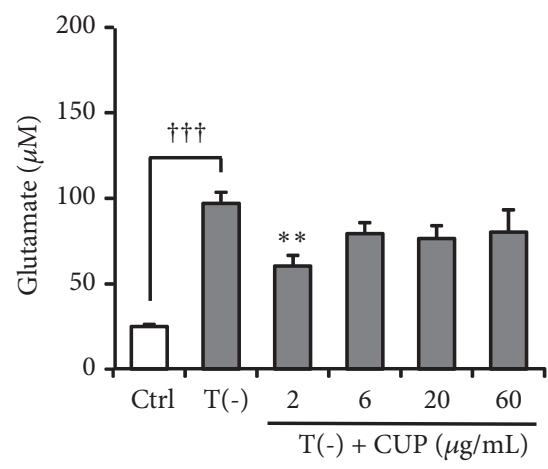

(a)

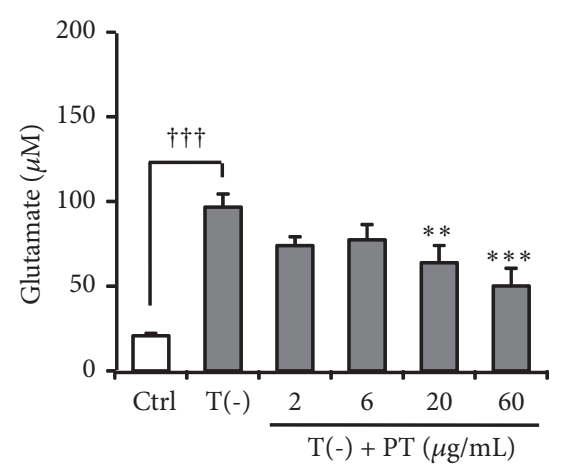

(b)

FIgURE 3: Effect of CUP or PT on TD-induced decrease in Glu uptake by cultured astrocytes. Astrocytes were cultured for 5 days in (1) Ctrl, thiamine-containing normal medium; (2) T(-), TD medium, or (3) T(-) medium containing CUP ((a) 2-60 $\mu \mathrm{g} / \mathrm{mL})$ or PT ((b) 2-60 $\mu \mathrm{g} / \mathrm{mL})$. Glu concentration of cultured Glu-containing medium $(100 \mu \mathrm{M})$ was evaluated after $5 \mathrm{~h}$. Data are presented as the mean \pm SEM $(\mathrm{n}=6) .{ }^{\dagger+\dagger} P$ $<0.001$ vs. Ctrl; $* * P<0.01$ and $* * * P<0.001$ vs. Glu: one-way ANOVA + Dunnett's test.

Figure 4 shows the effect of the Glu transporter inhibitors TBHA (nonspecific inhibitor of transporters including glutamate aspartate transporter [GLAST]) and DHK (specific inhibitor of glutamate transporter 1 [GLT-1]) on the amelioration of TD-induced decreased Glu uptake by YKS $(100 \mu \mathrm{g} / \mathrm{mL})$ and YKSCH $(140 \mu \mathrm{g} / \mathrm{mL})$. The decrease was significantly ameliorated by treatment with YKS or YKSCH, which was significantly blocked by TBHA $\left(F_{(3,20)}=61.701, P\right.$ $<0.001$ and $F_{(3,20)}=47.617, P<0.001$, respectively) but not $\operatorname{DHK}\left(F_{(3,20)}=48.329, P<0.001\right.$ and $F_{(3,20)}=26.505, P<0.001$, respectively) (Figure 4), suggesting that the amelioration by YKS and YKSCH predominantly occurs through effects on GLAST dysfunction under the present experimental conditions.

3.2. Effect of Drugs on Glu-Induced PC12 Cell Death. The suppressive effects of YKS and YKSCH on Glu-induced PC12 cell death were evaluated by MTT assay, showing that these treatments prevented cell death in a concentrationdependent manner $\left(F_{(5,30)}=92.811, P<0.001\right.$ and $F_{(5,30)}=$ $67.363, P<0.001$, respectively) (Figures $5(\mathrm{al})$ and $5(\mathrm{a} 2)$ ). The cell survival rate was converted to the amelioration rate to allow comparison between experiments (Figures 5(bl) and $5(\mathrm{~b} 2))$. The $30 \%$ effective dose $\left(\mathrm{ED}_{30}\right)$ for amelioration was calculated using the regression equation for the amelioration rate (Figure 5(c)). Each experiment was repeated 5 times, and the average $\mathrm{ED}_{30}$ was calculated. The average $\mathrm{ED}_{30}$ did not differ significantly between YKS $(51.4 \pm 20.8 \mu \mathrm{g} / \mathrm{mL})$ and YKSCH $(49.2 \pm 11.0 \mu \mathrm{g} / \mathrm{mL}$ ) (Figure 5(d)).

The inhibitory effects of CUP and PT on Glu-induced PC12 cell death were also examined. Glu-induced cell death was decreased by treatment with CUP $\left(F_{(5,30)}=21.289, P<\right.$ $\left.0.01 ; F_{(5,30)}=47.660, P<0.001\right)$ but not PT (Figure 6).

\section{Discussion}

This study presents two major findings. First, YKSCH facilitated the uptake of Glu into astrocytes subjected to TD, with weaker efficacy than that of YKS. Second, YKSCH inhibited
Glu-induced excitotoxicity in PC12 cells, with efficacy similar to that of YKS.

Recent reviews estimate that among adults $\geq 65$ years of age, half of the males and one-third of the females were at risk for inadequate thiamine intake [39, 40]. Thiamine is phosphorylated to thiamine diphosphate (TDP) by thiamine pyrophosphokinase. TDP is a cofactor for enzymes associated with glucose metabolism, including transketolase, pyruvate dehydrogenase, and $\alpha$-ketoglutarate dehydrogenase. Decreased activity of these TDP-dependent enzymes has been reported in neurodegenerative diseases such as Alzheimer's and Parkinson's diseases [41]. Previous studies have demonstrated that BPSD-like behaviors such as anxiety, depression, muricide, attacking, and startle responses, as well as impaired learning and memory are observed in TD rats and mice [42, 43]. Collins [44] and Robertson [45] have demonstrated that astrocytes are among the first cells to be affected by TD in advance of neuronal death. Symptomatic TD is associated with increased extracellular Glu concentrations in focal regions of the brain $[46,47]$. TD in cultured astrocytes resulted in decreased Glu uptake [36], caused by dysfunction of astrocyte Glu transporters [13]. In our previous study, we showed that YKS improved the decreased Glu uptake by cultured astrocytes under TD condition [13]. In the present study, effects of YKSCH as well as YKS were evaluated using the same system, and their efficacy was compared. As shown in Figure 2, the ameliorative effect of YKSCH on TD-induced decreased Glu uptake by astrocytes was weaker than that of YKS. This result suggests that the additional herbs in YKSCH (CUP and/or PT) might negatively affect Glu transport. However, unexpectedly, these herbs instead ameliorated the TD-induced decrease in Glu uptake (Figure 3). Another possible interpretation of this result is that CUP and/or PT might interfere with the ameliorative effects of YKS components when together in the formula of YKSCH. It should be noted that the ameliorative effect of YKSCH on TD-induced decreased Glu uptake was shown to occur through GLAST but not GLT-1 (Figure 4), a finding very similar to that for YKS in our previous report 


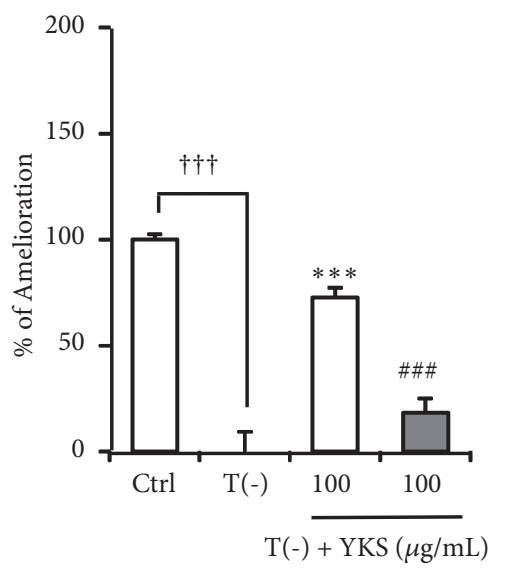

$\square:$ no inhibitor

$\square:$ TBHA

(a1)

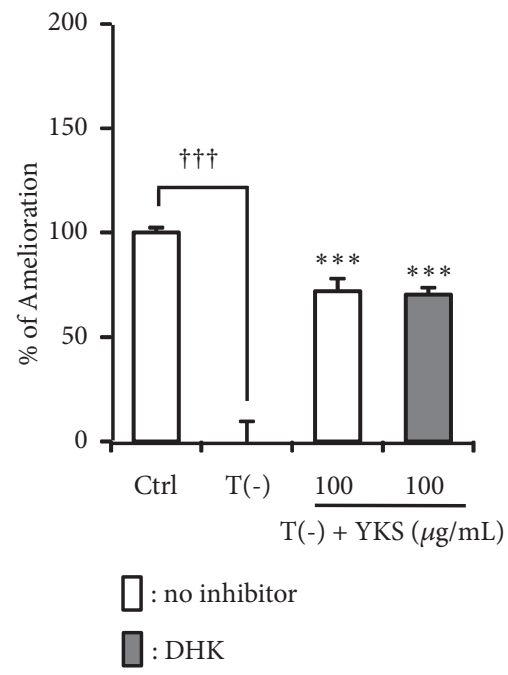

(b1)

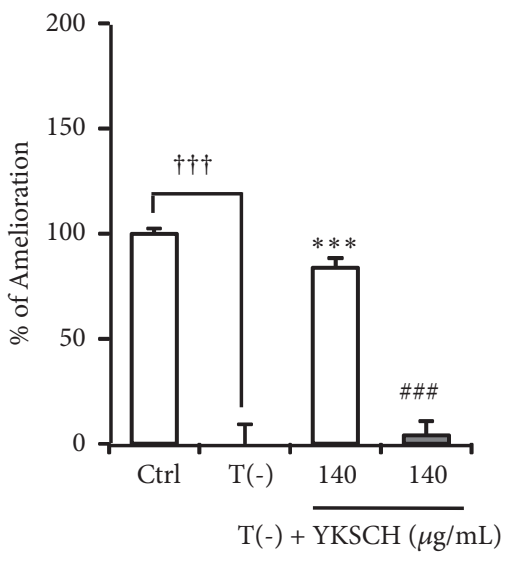

$\square:$ no inhibitor

$\square$ : ТBHA

(a2)

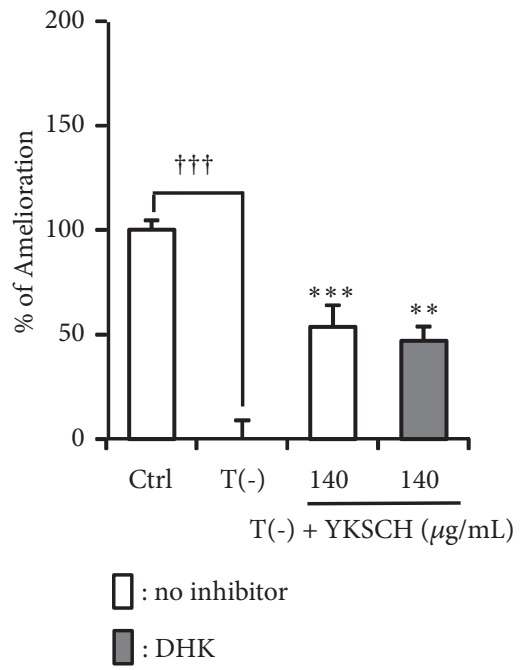

(b2)

FIGURE 4: Effects of TBHA and DHK on amelioration of TD-induced impairment of Glu uptake by YKS and YKSCH. Astrocytes were cultured for 5 days in (1) Ctrl, thiamine-containing normal medium, (2) T(-), TD medium; or (3) T(-) medium containing YKS (100 $\mu \mathrm{g} / \mathrm{mL}$ ) or YKSCH $(140 \mu \mathrm{g} / \mathrm{mL})$. Extracellular Glu concentration was measured $5 \mathrm{~h}$ after addition of $100 \mu \mathrm{M}$ Glu with $300 \mu \mathrm{M}$ TBHA (al, a2) or $1 \mathrm{mM}$ DHK (b1, b2). Data are presented as the mean \pm SEM $(\mathrm{n}=6) .{ }^{\dagger \dagger \dagger} P<0.001$ vs. Ctrl, $* * P<0.01, * * * P<0.001$ vs. T $(-)$, and ${ }^{\# \# \# ~} P<0.001$ vs. YKS or YKSCH: one-way ANOVA + Dunnett's test.

[13]. The difference of the effects of YKS and YKSCH is presumed to be due to the difference in the expression levels of protein and mRNA of GLAST, which should be clarified in the future study.

Alternatively, the amount of an active ingredient may be less or an inhibiting ingredient greater in $\mathrm{YKSCH}$ than in YKS. This possibility arises because the extraction efficiency of an ingredient from an herb is sometimes influenced by other herbs during the extraction process used to manufacture Kampo formulas. For example, the component that improves Glu uptake on TD astrocytes is reported to be glycyrrhizin and its metabolite glycyrrhetinic acid [14].
The glycyrrhizin content in the decoction of Glycyrrhiza with PT is lower than that of Glycyrrhiza alone [33, 34]. Thus, the glycyrrhizin content may be lower in $\mathrm{YKSCH}$ than YKS, thereby weakening the effect of YKSCH. The Japanese Pharmacopoeia 17th edition, supplement I, states that the daily dose of YKS (3.25 g of dried extract) contains $10-30 \mathrm{mg}$ glycyrrhizin. Thus, the maximum concentration of glycyrrhizin in culture medium containing $100 \mu \mathrm{g} / \mathrm{mL}$ YKS is $1122 \mathrm{nM}$. Considering our previous study showing the dose-response relationship of glycyrrhizin on Glu uptake by TD astrocytes [14], this maximum concentration of glycyrrhizin is the lower limit of the concentration showing 


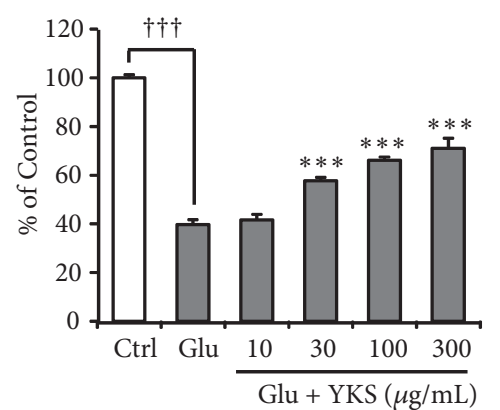

(a1)

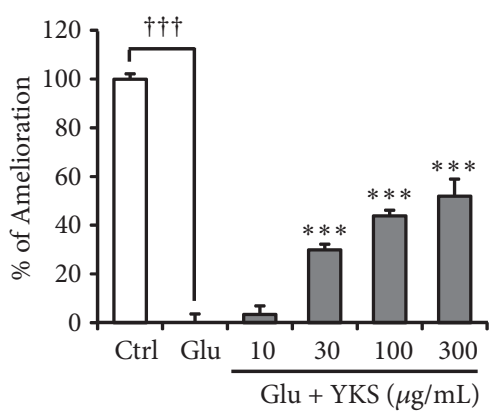

(b1)

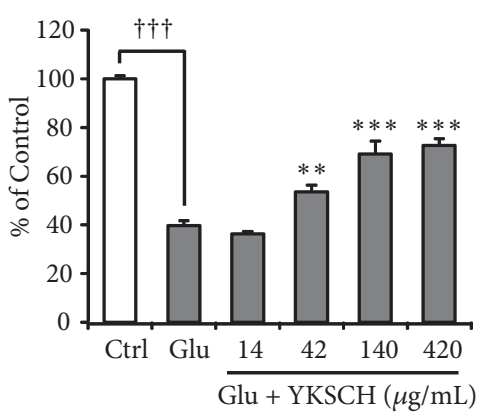

(a2)

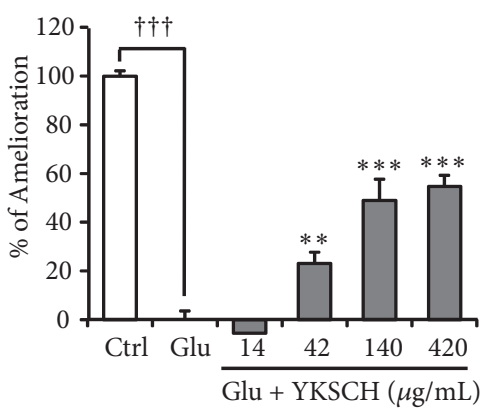

(b2)

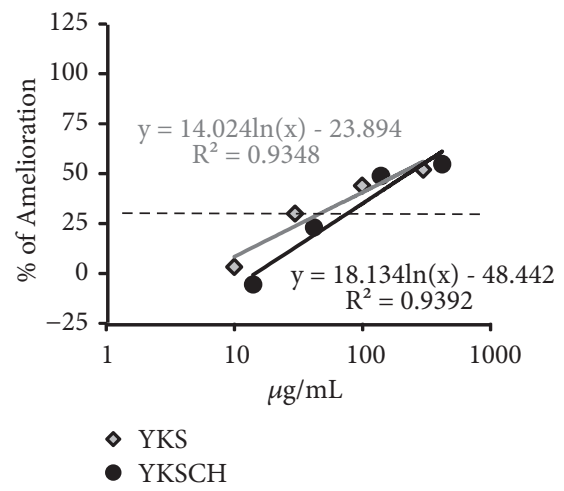

(c)

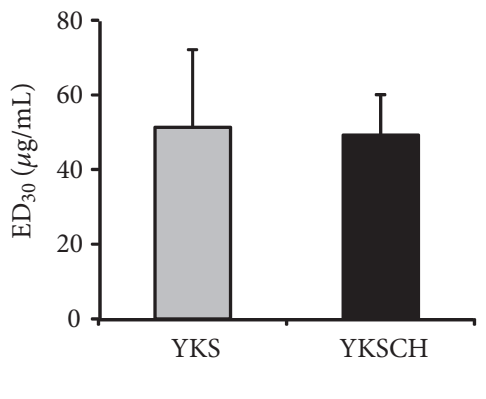

(d)

Figure 5: Effect of YKS or YKSCH on Glu-induced PC12 cell death. PC12 cells were incubated for $24 \mathrm{~h}$ in media containing $8 \mathrm{mM}$ Glu + YKS $(10-300 \mu \mathrm{g} / \mathrm{mL})$ or YKSCH $(14-420 \mu \mathrm{g} / \mathrm{mL})$. The control medium (Ctrl) contained no Glu. (a1, a2) Survival rate calculated as \%MTT activity relative to control PC12 cells $(\mathrm{n}=6)$. ( $\mathrm{b} 1, \mathrm{~b} 2)$ Amelioration rate as determined from survival rate. $(\mathrm{c}) 30 \%$ effective dose $\left(\mathrm{ED}_{30}\right)$ as calculated from the regression equation for the amelioration rate. (d) Comparison of the average $\mathrm{ED}_{30}$ between YKS and YKSCH. Data are presented as the mean \pm SEM $((\mathrm{a} 1),(\mathrm{a} 2),(\mathrm{b} 1)$, and $(\mathrm{b} 2): \mathrm{n}=6 ;(\mathrm{d}): \mathrm{n}=5),{ }^{\dagger \dagger \dagger} P<0.001$ vs. Ctrl; $* * P<0.01$, and $* * * P<0.001$ vs. Glu: one-way ANOVA + Dunnett's test.

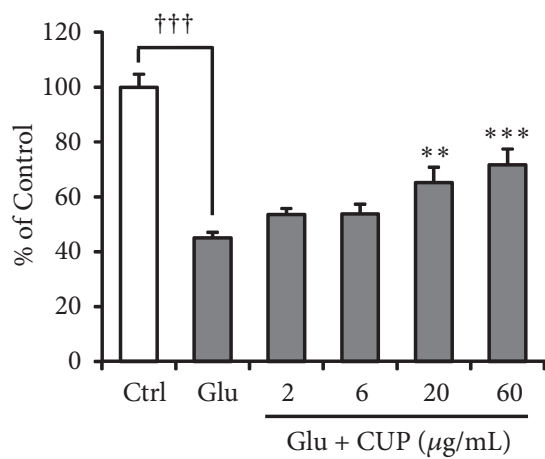

(a)

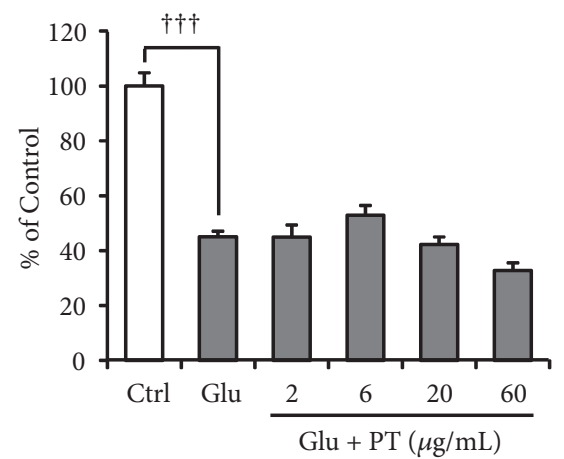

(b)

Figure 6: Effect of CUP or PT on Glu-induced PC12 cell death. PC12 cells were incubated for $24 \mathrm{~h}$ in medium containing $8 \mathrm{mM}$ Glu + CUP ((a) $2-60 \mu \mathrm{g} / \mathrm{mL}$ ) or PT ((b) 2-60 $\mu \mathrm{g} / \mathrm{mL}$ ). The control medium (Ctrl) contained no Glu. Survival rate calculated as the $\%$ MTT activity relative to control PC12 cells. Data are presented as the mean \pm SEM $(\mathrm{n}=6) .{ }^{\dagger \dagger \dagger} P<0.001$ vs. Ctrl; $* * P<0.01$ and $* * * P<0.001$ vs. Glu: one-way ANOVA + Dunnett's test.

improvement in TD-induced decreased Glu uptake by astrocytes. Although the difference in glycyrrhizin content between YKS and YKSCH might partially contribute to their differing efficacies with respect to Glu uptake, glycyrrhizin content alone cannot explain this difference. Considering that YKS components showing improving effects on Glu uptake are found not only in Glycyrrhiza but also in Bupleurum root, Poria sclerotium, Japanese Angelica root, and Cnidium rhizome [14], the difference in Glu uptake efficacy between YKS and YKSCH may result from differences in additive and/or synergic effects of their constituent plants. 
We previously demonstrated that YKS inhibited Gluinduced cell death of primary cultured neuron [48] and PC12 cells [49], indicating that YKS has a protective effect against Glu neurotoxicity as one of the mechanisms underlying its neuropsychopharmacological effects [50]. In the present study, the inhibitory effects of YKSCH on Glu-induced PC12 cell death were examined, and its efficacy was compared to that of YKS. As shown in Figure 5, the efficacy of these two drugs is similar, suggesting that the YKS components in the YKSCH formula are responsible for the inhibitory effects of YKSCH. However, our data do not rule out the involvement of other additional herbs, because the neuroprotective effect has been found in CUP alone (Figure 6), as confirmed by previous reports [51, 52].

Several studies suggest that PC12 cells do not express a normal profile of NMDA receptors and that Glu cytotoxicity is mediated by the oxidative glutamatergic toxicity pathway, which is related to the system $\mathrm{Xc}^{-}$[53-58]. The competition by Glu for the system $\mathrm{Xc}^{-}$induces an imbalance in the homeostasis of cysteine, the precursor of glutathione. Thus, the inhibition of cystine uptake by high Glu concentrations may give rise to the inability to maintain intracellular glutathione levels needed to protect against oxidative injury [56]. We demonstrated previously that YKS protects against Glu cytotoxicity by augmenting gene expression of the system $\mathrm{Xc}^{-}$subunits $4 \mathrm{~F} 2 \mathrm{hc}$ and $\mathrm{xCT}$ [15]. YKSCH is thought to exert its effects through the same mechanism as YKS.

\section{Conclusion}

We provide evidence that the pharmacological actions of YKS and YKSCH differ in some respects but are similar in others. YKSCH is less effective than YKS at ameliorating TDinduced decreases in Glu uptake by astrocytes, while YKSCH has similar inhibitory effects to YKS on Glu-induced PC12 cell death. These findings might be related to the observation that the antiaggressive effect of YKSCH is sometimes weaker than that of YKS. Additional studies are required to clarify the mechanisms underlying the differences in efficacy between these drugs and the involvement of PT and CUP in YKSCH.

\section{Data Availability}

The data used to support the findings of this study are available from the corresponding author upon request and permission.

\section{Conflicts of Interest}

All authors are employees of Tsumura \& Co., who funded the present study. This employer provided support in the form of salaries for all authors but had no additional role in the study design, data collection and analysis, decision to publish, or preparation of the paper. This research did not receive any other funding and was performed as a part of the employment.

\section{Authors' Contributions}

Zenji Kawakami, Yuji Omiya, and Kazushige Mizoguchi designed the experiments and prepared the manuscript. Zenji Kawakami performed the experiments and analyzed the data. All authors discussed the results and commented on the paper.

\section{Acknowledgments}

The authors thank all members of their group in Tsumura Kampo Research Laboratories for stimulating discussions.

\section{Supplementary Materials}

Supplementary Figure 1: cultured rat cortical astrocytes. Astrocytes were fixed with $4 \%$ paraformaldehyde, stained with monoclonal antibodies for GFAP (brown), a specific marker for the astrocyte, and counterstained with hematoxylin (blue). Scale bar $=100 \mu \mathrm{m}$. (Supplementary Materials)

\section{References}

[1] K. Iwasaki, T. Satoh-Nakagawa, M. Maruyama et al., "A randomized observer-blind, controlled trial of the traditional Chinese medicine yi-gan san for improvement of behavioral and psychological symptoms and activities of daily living dementia patients," Journal of Clinical Psychiatry, vol. 66, no. 2, pp. 248252, 2005.

[2] K. Iwasaki, M. Maruyama, N. Tomita et al., "Effects of the traditional Chinese herbal medicine Yi-Gan San for cholinesterase inhibitor-resistant visual hallucinations and neuropsychiatric symptoms in patients with dementia with Lewy bodies," Journal of Clinical Psychiatry, vol. 66, no. 12, pp. 1612-1613, 2005.

[3] Y. Matsuda, T. Kishi, H. Shibayama, and N. Iwata, "Yokukansan in the treatment of behavioral and psychological symptoms of dementia: a systematic review and meta-analysis of randomized controlled trials," Journal of Psychopharmacology, vol. 28, no. 1, pp. 80-86, 2013.

[4] S. Matsunaga, T. Kishi, and N. Iwata, "Yokukansan in the treatment of behavioral and psychological symptoms of dementia: an updated meta-analysis of randomized controlled trials," Journal of Alzheimer's Disease, vol. 54, no. 2, pp. 635-643, 2016.

[5] S. Iizuka, Z. Kawakami, S. Imamura et al., "Electronmicroscopic examination of effects of yokukansan, a traditional Japanese medicine, on degeneration of cerebral cells in thiamine-deficient rats," Neuropathology, vol. 30, no. 5, pp. 524-536, 2010.

[6] Y. Ikarashi, S. Iizuka, S. Imamura et al., "Effects of yokukansan, a traditional Japanese medicine, on memory disturbance and behavioral and psychological symptoms of dementia in thiamine-deficient rats," Biological \& Pharmaceutical Bulletin, vol. 32, no. 10, pp. 1701-1709, 2009.

[7] A. Takeda, H. Itoh, H. Tamano, M. Yuzurihara, and N. Oku, "Suppressive effect of Yokukansan on excessive release of glutamate and aspatate in the hippocampus of zinc-deficient rats," Nutritional Neuroscience, vol. 11, no. 1, pp. 41-46, 2008.

[8] A. Takeda, H. Iwaki, K. Ide, H. Tamano, and N. Oku, "Therapeutic effect of Yokukansan on social isolation-induced aggressive behavior of zinc-deficient and pair-fed mice," Brain Research Bulletin, vol. 87, no. 6, pp. 551-555, 2012. 
[9] A. Nishi, T. Yamaguchi, K. Sekiguchi et al., "Geissoschizine methyl ether, an alkaloid in Uncaria hook, is a potent serotonin $_{1 A}$ receptor agonist and candidate for amelioration of aggressiveness and sociality by yokukansan," Neuroscience, vol. 207, pp. 124-136, 2012.

[10] H. Fujiwara, S. Takayama, K. Iwasaki et al., "Yokukansan, a traditional Japanese medicine, ameliorates memory disturbance and abnormal social interaction with anti-aggregation effect of cerebral amyloid $\beta$ proteins in amyloid precursor protein transgenic mice," Neuroscience, vol. 180, pp. 305-313, 2011.

[11] K. Sekiguchi, S. Imamura, T. Yamaguchi et al., "Effects of yokukansan and donepezil on learning disturbance and aggressiveness induced by intracerebroventricular injection of amyloid $\beta$ protein in mice," Phytotherapy Research, vol. 25, no. 4, pp. 501-507, 2011.

[12] M. Tabuchi, K. Mizuno, K. Mizoguchi, T. Hattori, and Y. Kase, "Yokukansan and yokukansankachimpihange ameliorate aggressive behaviors in rats with cholinergic degeneration in the nucleus basalis of meynert," Frontiers in Pharmacology, vol. 8, p. 235, 2017.

[13] Z. Kawakami, H. Kanno, T. Ueki et al., "Neuroprotective effects of yokukansan, a traditional japanese medicine, on glutamatemediated excitotoxicity in cultured cells," Neuroscience, vol. 159, no. 4, pp. 1397-1407, 2009.

[14] Z. Kawakami, Y. Ikarashi, and Y. Kase, "Glycyrrhizin and its metabolite $18 \beta$-glycyrrhetinic acid in glycyrrhiza, a constituent herb of yokukansan, ameliorate thiamine deficiency-induced dysfunction of glutamate transport in cultured rat cortical astrocytes," European Journal of Pharmacology, vol. 626, no. 2-3, pp. 154-158, 2010.

[15] H. Kanno, Z. Kawakami, K. Mizoguchi, Y. Ikarashi, and Y. Kase, "Yokukansan, a kampo medicine, protects PC12 cells from glutamate-induced death by augmenting gene expression of cystine/glutamate antiporter system Xc-," PLOS ONE, vol. 9, no. 12, Article ID el16275, 2014.

[16] K. Terawaki, Y. Ikarashi, K. Sekiguchi, Y. Nakai, and Y. Kase, "Partial agonistic effect of yokukansan on human recombinant serotonin 1A receptors expressed in the membranes of Chinese hamster ovary cells," Journal of Ethnopharmacology, vol. 127, no. 2, pp. 306-312, 2010.

[17] T. Ueki, K. Mizoguchi, T. Yamaguchi et al., "Yokukansan increases $5-\mathrm{HT}_{1 A}$ receptors in the prefrontal cortex and enhances $5-\mathrm{HT}_{1 A}$ receptor agonist-induced behavioral responses in socially isolated mice," Evidence-Based Complementary and Alternative Medicine, vol. 2015, Article ID 726471, 9 pages, 2015.

[18] N. Egashira, K. Iwasaki, A. Ishibashi et al., "Repeated administration of Yokukansan inhibits DOI-induced head-twitch response and decreases expression of 5-hydroxytryptamine (5HT)2A receptors in the prefrontal cortex," Progress in NeuroPsychopharmacology \& Biological Psychiatry, vol. 32, no. 6, pp. 1516-1520, 2008.

[19] T. Ueki, K. Mizoguchi, T. Yamaguchi et al., "Yokukansan, a traditional Japanese medicine, decreases head-twitch behaviors and serotonin $2 \mathrm{~A}$ receptors in the prefrontal cortex of isolationstressed mice," Journal of Ethnopharmacology, vol. 166, pp. 2330, 2015.

[20] J. H. Lyu and H.-T. Lee, "Effects of dried Citrus unshiu peels on gastrointestinal motility in rodents," Archives of Pharmacal Research, vol. 36, no. 5, pp. 641-648, 2013.

[21] World Health Organization, WHO International Standard Terminologies on Traditional Medicine in the Western Pacific Region, World Health Organization, Western Pacific Region, 2007.
[22] J.-S. Yoon, J.-C. Seo, and S.-W. Han, "Pinelliae Rhizoma herbalacupuncture solution induced apoptosis in human cervical cancer cells, SNU-17," American Journal of Chinese Medicine, vol. 34, no. 3, pp. 401-408, 2006.

[23] J. Miyazawa, "Psychiatric pharmacology: study of the clinical efficacy of yokukansankachimpihange on Alzheimer's disease," Psychiatry, vol. 14, no. 6, pp. 535-542, 2009.

[24] A. Magome, "Effect of Yokukansankachimpihange on dementia-Including the point of view of oriental medicine," Psychiatry, vol. 18, no. 1, pp. 108-114, 2008.

[25] Y. Manabe, H. Yokoyama, H. Fujishiro, M. Rho, and K. Kosaka, "A preliminary trial in the efficacy of the traditional herbal medicine of yokukansankachimpihange for the management of behavioral and psychological symptoms in dementia," Japanese Journal of Geriatric Psychiatry, vol. 27, no. 4, pp. 438-447, 2016.

[26] E. Katsumoto, T. Ishida, K. Kinoshita et al., "Efficacy and safety of yokukansankachimpihange on BPSD," Japanese Journal of Medicine and Pharmaceutical Science, vol. 73, no. 7, pp. 846-853, 2016.

[27] K. Meguro and S. Yamaguchi, "Decreased behavioral abnormalities after treatment with combined donepezil and yokukansankachimpihange in alzheimer disease: an observational study. The osaki-tajiri project," Neurology and Therapy, vol. 7, no. 2, pp. 333-340, 2018.

[28] R. Arita, T. Yoshino, M. Ohgishi et al., “The efficacy and safety of yokukansankachimpihange for treating behavioral and psychological symptoms of dementia in patients with Alzheimer's disease: an open-label pilot study," Advances in Alzheimer's Disease, vol. 7, no. 4, pp. 141-152, 2018.

[29] K. Mizuno, M. Tabuchi, S. Imamura et al., "Effects of Yokukansan and yokukansankachimpihange on neuropsychiatric and gastrointestinal symptoms in BPSD (thiamine-deficient) model rat," Japanese Pharmacology \& Therapeutics, vol. 44, no. 2, pp. 195-206, 2016.

[30] H. Tamano, F. Kan, N. Oku, and A. Takeda, "Ameliorative effect of Yokukansan on social isolation-induced aggressive behavior of zinc-deficient young mice," Brain Research Bulletin, vol. 83, no. 6, pp. 351-355, 2010.

[31] H. Tamano, E. Yusuke, K. Ide, and A. Takeda, "Influences of yokukansankachimpihange on aggressive behavior of zincdeficient mice and actions of the ingredients on excessive neural exocytosis in the hippocampus of zinc-deficient rats," Journal of Experimental Animal Science, vol. 65, no. 4, pp. 353-361, 2016.

[32] I. Sakakibara, S. Terabayashi, M. Kubo, M. Higuchi, H. Sasaki, and M. Okada, "Evaluation of Gou-teng (hooks and stems of uncariae plants) III. Hypotensive principle from Uncaria rhynchophylla and alteration of its content on extraction process," Journal of Natural Medicines, vol. 53, no. 6, pp. 308-312, 1999.

[33] T. Tomimori and M. Yoshimoto, "Quantitative variation of glycyrrhizin in the decoction of glycyrrhizae radix mixed with other crude drugs," Shoyakugaku Zasshi, vol. 34, no. 2, pp. 138$144,1980$.

[34] Z. Li, S. Xiao, N. Ai, K. Luo, X. Fan, and Y. Cheng, "Derivative multiple reaction monitoring and single herb calibration approach for multiple components quantification of traditional Chinese medicine analogous formulae," Journal of Chromatography A, vol. 1376, pp. 126-142, 2015.

[35] B. H. J. Juurlink and W. Walz, "Neural cell culture techniques," in Cell Neurobiology Techniquess. Neuromethods, A. A. Boulton, G. B. Baker, and A. N. Bateson, Eds., vol. 33, pp. 53-102, Humana Press Inc., Totowa, NJ, USA, 1998. 
[36] A. S. Hazell, P. Pannunzio, K. V. R. Rao, D. V. Pow, and A. Rambaldi, "Thiamine deficiency results in downregulation of the GLAST glutamate transporter in cultured astrocytes," Glia, vol. 43, no. 2, pp. 175-184, 2003.

[37] K. Abe, Y. Abe, and H. Saito, "Evaluation of L-glutamate clearance capacity of cultured rat cortical astrocytes," Biological \& Pharmaceutical Bulletin, vol. 23, no. 2, pp. 204-207, 2000.

[38] M. Sakai, A. Miyazaki, H. Hakamata et al., "Lysophosphatidylcholine plays an essential role in the mitogenic effect of oxidized low density lipoprotein on murine macrophages," The Journal of Biological Chemistry, vol. 269, no. 50, pp. 31430-31435, 1994.

[39] S. Ter Borg, S. Verlaan, J. Hemsworth et al., "Micronutrient intakes and potential inadequacies of community-dwelling older adults: a systematic review," British Journal of Nutrition, vol. 113, no. 8, pp. 1195-1206, 2015.

[40] R. Hoffman, "Thiamine deficiency in the Western diet and dementia risk," British Journal of Nutrition, vol. 116, no. 1, pp. 188-189, 2016.

[41] R. F. Butterworth, "Thiamin deficiency and brain disorders," Nutrition Research Reviews, vol. 16, no. 2, pp. 277-283, 2003.

[42] O. Nakagawasai, T. Tadano, F. Niijima, K. Tan-No, and K. Kisara, "Immunohistochemical estimation of rat brain somatostatin on avoidance learning impairment induced by thiamine deficiency," Brain Research Bulletin, vol. 51, no. 1, pp. 47-55, 2000.

[43] A. Murata, O. Nakagawasai, F. Yamadera et al., "Dysfunction of serotonergic systems in thiamine-deficient diet fed mice: Effects of SSRI on abnormality induced by thiamine deficiency," Japanese Journal of Neuropsychopharmacology, vol. 24, no. 2, pp. 93-99, 2004.

[44] G. H. Collins, "Glial cell changes in the brain stem of thiaminedeficient rats," The American Journal of Pathology, vol. 50, no. 5, pp. 791-814, 1967.

[45] D. M. Robertson, S. M. Wasan, and D. B. Skinner, "Ultrastructural features of early brain stem lesions of thiamine-deficient rats," The American Journal of Pathology, vol. 52, no. 5, pp. 10811097, 1968.

[46] A. S. Hazell, R. F. Butterworth, and A. M. Hakim, "Cerebral vulnerability is associated with selective increase in extracellular glutamate concentration in experimental thiamine deficiency," Journal of Neurochemistry, vol. 61, no. 3, pp. 1155-1158, 1993.

[47] P. J. Langlais and S. X. Zhang, "Extracellular glutamate is increased in thalamus during thiamine deficiency-induced lesions and is blocked by MK-801," Journal of Neurochemistry, vol. 61, no. 6, pp. 2175-2182, 1993.

[48] Z. Kawakami, Y. Ikarashi, and Y. Kase, "Isoliquiritigenin is a novel NMDA receptor antagonist in kampo medicine yokukansan," Cellular and Molecular Neurobiology, vol. 31, no. 8, pp. 1203-1212, 2011.

[49] Z. Kawakami, H. Kanno, Y. Ikarashi, and Y. Kase, "Yokukansan, a kampo medicine, protects against glutamate cytotoxicity due to oxidative stress in PC12 cells," Journal of Ethnopharmacology, vol. 134, no. 1, pp. 74-81, 2011.

[50] Y. Ikarashi and K. Mizoguchi, "Neuropharmacological efficacy of the traditional Japanese Kampo medicine yokukansan and its active ingredients," Pharmacology \& Therapeutics, vol. 166, pp. 84-95, 2016.

[51] J. Cho, "Antioxidant and neuroprotective effects of hesperidin and its aglycone hesperetin," Archives of Pharmacal Research, vol. 29, no. 8, pp. 699-706, 2006.
[52] S.-L. Hwang and G.-C. Yen, "Neuroprotective effects of the citrus flavanones against $\mathrm{H}_{2} \mathrm{O}_{2}$-induced cytotoxicity in $\mathrm{PC1} 2$ cells," Journal of Agricultural and Food Chemistry, vol. 56, no. 3, pp. 859-864, 2008.

[53] D. Schubert, H. Kimura, and P. Maher, "Growth factors and vitamin E modify neuronal glutamate toxicity," Proceedings of the National Acadamy of Sciences of the United States of America, vol. 89, no. 17, pp. 8264-8267, 1992.

[54] P. Froissard and D. Duval, "Cytotoxic effects of glutamic acid on PC12 cells," Neurochemistry International, vol. 24, no. 5, pp. 485-493, 1994.

[55] M. A. Edwards, R. A. Loxley, A. J. Williams, M. Connor, and J. K. Phillips, "Lack of functional expression of NMDA receptors in PC12 cells," NeuroToxicology, vol. 28, no. 4, pp. 876-885, 2007.

[56] C. F. Pereira and C. R. D. Oliveira, "Oxidative glutamate toxicity involves mitochondrial dysfunction and perturbation of intracellular Ca2 ${ }^{+}$homeostasis," Neuroscience Research, vol. 37, no. 3, pp. 227-236, 2000.

[57] S. Penugonda, S. Mare, G. Goldstein, W. A. Banks, and N. Ercal, "Effects of N-acetylcysteine amide (NACA), a novel thiol antioxidant against glutamate-induced cytotoxicity in neuronal cell line PC12," Brain Research, vol. 1056, no. 2, pp. 132-138, 2005.

[58] M. Lo, Y.-Z. Wang, and P. W. Gout, "The xc- cystine/glutamate antiporter: A potential target for therapy of cancer and other diseases," Journal of Cellular Physiology, vol. 215, no. 3, pp. 593602,2008 . 


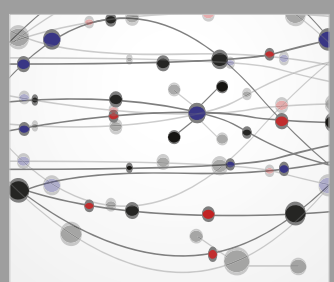

The Scientific World Journal
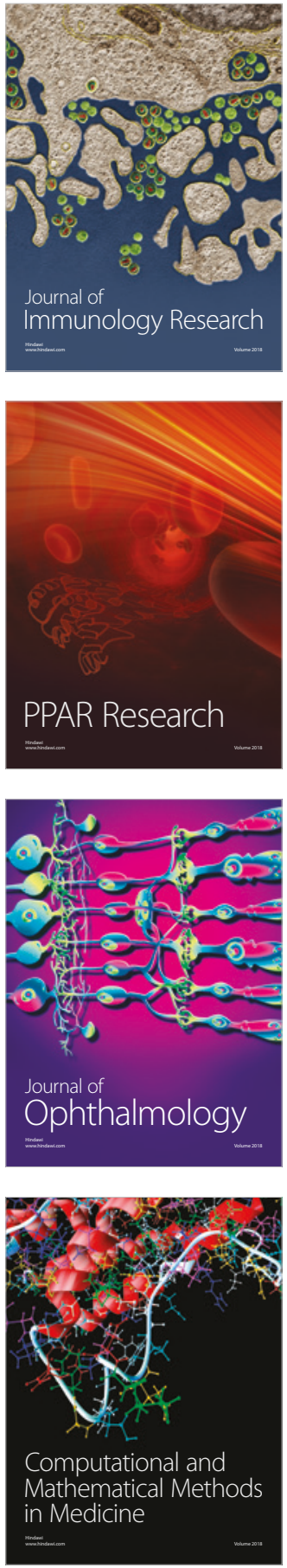

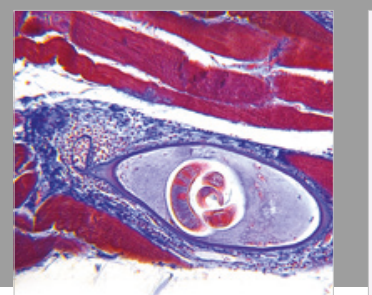

Gastroenterology Research and Practice

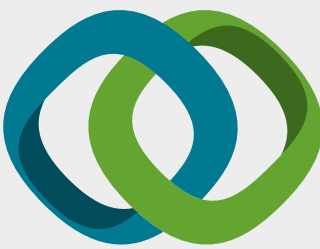

\section{Hindawi}

Submit your manuscripts at

www.hindawi.com
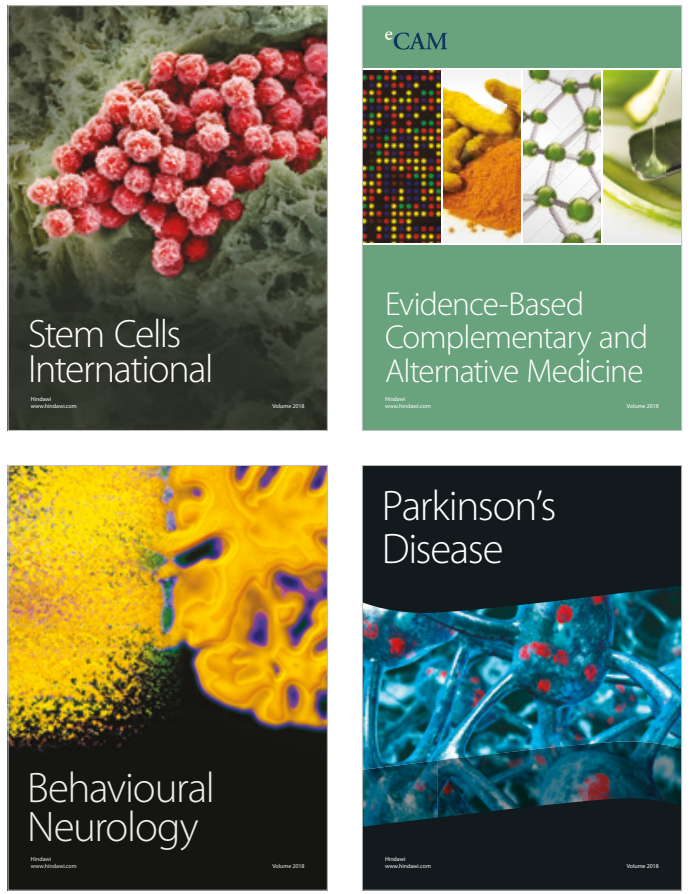

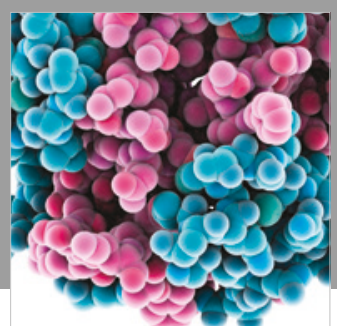

ournal of

Diabetes Research

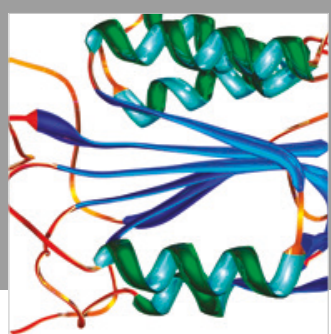

Disease Markers
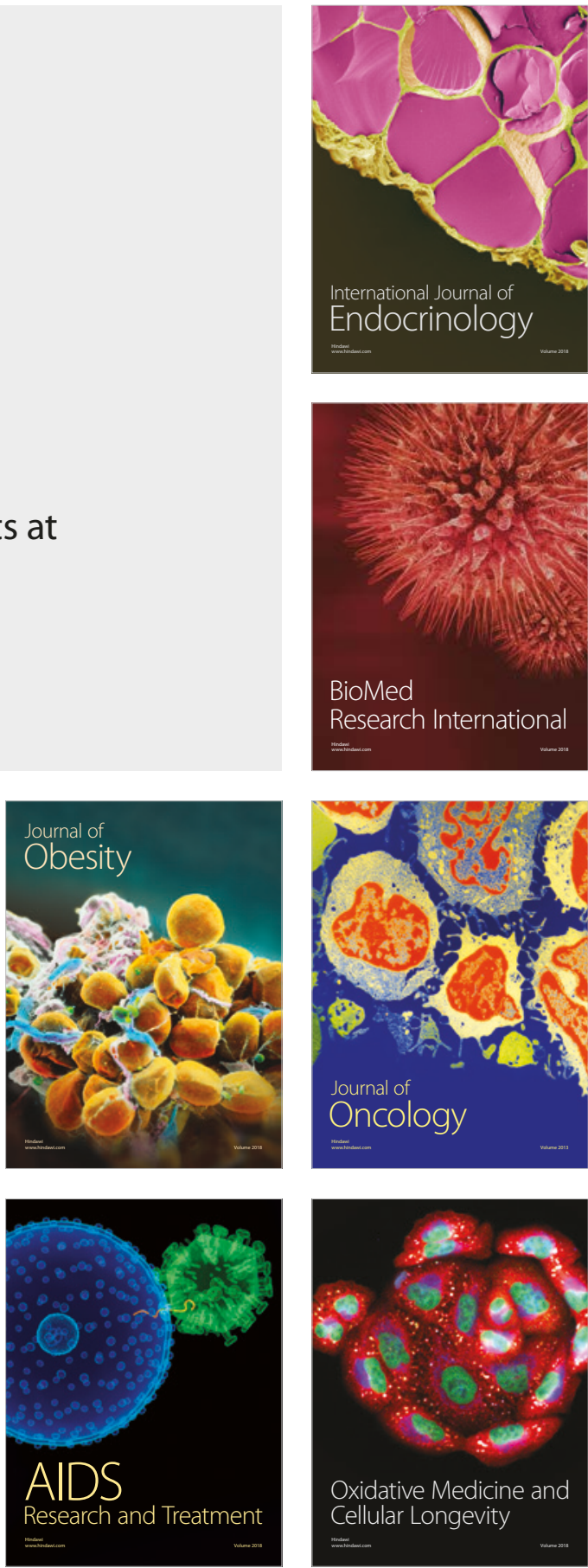